\title{
Homology versus Convergence in Resolving Transphyletic Correspondences of Brain Organization
}

\author{
Nicholas J. Strausfeld ${ }^{\mathrm{a}}$ Frank Hirth ${ }^{\mathrm{b}}$ \\ a Department of Neuroscience and Centre for Insect Science, University of Arizona, Tucson, Ariz., USA; \\ ${ }^{b}$ Department of Neuroscience, Institute of Psychiatry, King's College London, London, UK
}

\section{Key Words}

Arthropods · Basal ganglia - Brain evolution - Central

complex · Convergence · Homology · Vertebrate

\begin{abstract}
Due to the largely absent fossil record, phylogenetic comparisons of brain structures rely on the analysis of nervous systems in extant taxa, many of which appear to have distinctive and dissimilar neural arrangements. The use of a multitude of comparative criteria, including developmental genetics, phylogenomics and neural circuit architecture, has recently resolved a highly conserved structural and functional ground pattern organization in the arthropod central complex and vertebrate basal ganglia. The minuteness of resemblance is exemplified by orthologous action selection circuits that are formed by homologous gene networks and which can lead to similar pathologies and behavioral disorders. It has been argued, however, that these similarities of brain centers can only be due to convergent evolution. What is still missing is a plausible scenario to explain how convergence could result in such a multitude of similarities and minuteness of resemblances, including gene expression, functional attributes and pathologies. In contrast, homology by common descent is the more parsimonious explanation. Moreover, the divergent elaboration of arthropod central
\end{abstract}

\section{KARGER}

E-Mail karger@karger.com

www.karger.com/bbe complex and vertebrate basal ganglia does not obscure their shared ground pattern organization and thus genealogical correspondence.

\section{Introduction}

More than a decade before Darwin's 'On the Origin of Species' [1859], the British biologist Richard Owen introduced the term 'homology' with reference to vertebrate forelimbs in order to identify them as the 'same organ in different animals under every variety of form and function' [Owen, 1843]. Despite their personal differences, Darwin sanctioned Owen's criteria for homology, but emphasized common ancestry, when he referred to '... the relative position or connexion in homologous parts; they may differ to almost any extent in form and size, and yet remain connected together in the same invariable order' [Darwin, 1859]. Later in life, Owen used his definition of homology to adopt the position, first made by Geoffroy Saint-Hilaire [1820], that invertebrate and vertebrate central nervous systems (CNS) were homologous

\section{Dr. Frank Hirth}

Department of Neuroscience, Institute of Psychiatry

King's College London, 16 De Crespigny Park, PO Box 37

London SE5 8AF (UK)

E-Mail frank.hirth@ kcl.ac.uk

Prof. Nicholas J. Strausfeld

Department of Neuroscience and Centre for Insect Science, University of Arizona 611 Gould-Simpson Building

Tucson, AZ 85721-0106 (USA)

E-Mail flybrain@neurobio.arizona.edu 
[Owen, 1883]. Subsequently, the accumulation of paleontological, anatomical and embryological evidence established structural homology as a genealogical correspondence between characters that are shared due to common ancestry [Mindell and Meyer, 2001; Ghiselin, 2005].

An understanding of the genetic mechanisms underlying genealogical correspondence began to emerge with the advent of molecular biology and genome sequencing. Comparative data from developmental genetics and phylogenomics revealed similarities in the sequence and organization of genes that orchestrate the formation of vertebrate forelimbs and other morphological characters across different species [Shubin et al., 1997, 2009]. These data extend the identification of homology based on morphological structure to include gene expression and function. Nowadays, these are all used as additional criteria to deduce genealogical relationships [Telford and Budd, 2003; Wagner, 2007; Carroll, 2008; Telford and Copley, 2011], and they refine and improve phylogenetic considerations [e.g. Dunn et al., 2008; Mallatt et al., 2012].

Yet, despite such advances, phylogenetic comparisons and the identification of homologies remain contentious, particularly across phyla and with respect to certain morphologies, such as eyes, circulatory systems and the CNS. For these, except for a few extraordinary exceptions [Strausfeld, 2011; Ma et al., 2012; Tanaka et al., 2013], the fossil record has remained elusive thereby restricting analyses to comparisons of living taxa.

\section{Phylogenetic Comparisons of Neuronal Structures}

To bridge gaps in fossil history, the paleontologist Gaylord Simpson proposed that in the absence of a fossil record as many features as possible should be used to compare different extant taxa if the aim was to deduce ancestry. To distinguish common descent from convergence, Simpson [1961] proposed that the identification of homologous structures has to rely on criteria that are based on degrees of similarities, including the minuteness of resemblance and the multiplicity of similarities. With regard to the nervous system, these include similarity of topology, topography, embryological derivation, morphological features, such as neural architectures, circuitry, neurochemical attributes, physiological properties, gene expression and behavioral outcomes of neuronal activity, including pathologies [see also Butler and Hodos, 2005].

Simpson's approach to resolving homology has resonated in many fields of evolutionary biology including those in which phyletic relationships have contributed to understanding principles of neural organization. These include the genetic specification of homologous neuronal subgroups in insect hemi-segments [Patel et al., 1992], the genetic identification of correspondences of brain segments in vertebrates, insects and tunicates [Hirth et al., 2003; Holland et al., 2013], the development and evolution of the neural crest [Bronner and LeDouarin, 2012] and the homologous organization of vertebrate basal ganglia [Medina and Reiner, 1995; Stephenson-Jones et al., 2011, 2012]. More recently, identifying a multiplicity of correspondences in vertebrate and arthropod forebrains has resolved a highly conserved structural and functional organization of the arthropod central complex and vertebrate basal ganglia, both centers pivotal to action selection in behavior [Strausfeld and Hirth, 2013].

\section{Is Convergence a Useful Explanation for the Evolution of Brains?}

Such claims do not sit well with those who take the view that a multitude of similarities between the brains of distantly related species should naturally be assigned to convergent evolution [Striedter, 2005; Moroz, 2009; Northcutt, 2012; Farries 2013]. The reasons given for rejecting cross-phyletic brain homologies appear mainly to revolve around four issues. The first of these is the belief that dissimilarities of nervous systems in arthropods and vertebrates are too profound to support homology. This stance is attached to the second issue: the notion that only four of the extant metazoan phyla possess brains, the idea being that as these phyla are distantly related, their brains must therefore have evolved independently and repeatedly at least four times [Morris, 2003; Northcutt, 2012]. Third is the idea that the protostome-deuterostome ancestor was too simple to have possessed a complex brain [Farries, 2013], an argument rooted in the assumption that the first bilateral metazoans possessed a net-like nervous system [Moroz, 2009; Northcutt, 2012]. Another position is the refutation that homologous genes and gene networks do not necessarily establish the identity of a character [Farries, 2013], a conclusion directly in conflict with the established role of character identity genes and networks (ChINs) that specify morphological characters and hence can be used as homology criteria [Wagner, 2007; Carroll, 2008; Hirth, 2010].

There are indeed abundant dissimilarities across nervous systems, especially between distantly related taxa, such as annelids, arthropods and vertebrates, and there are profound differences between these three and mol- 
luscan nervous systems that have undergone torsion. However, differences alone do not have explanatory power, nor do generalizations that are used to justify objections to genealogical correspondences, such as the claim that GABAergic neurons associated with the central complex conduct towards that center not away from it [Farries, 2013], despite the fact that this was not demonstrated in any of the cited papers describing GABAergic neurons. In fact, claiming homoplasy on the basis of disparity can be profoundly misleading. For example, compared just across Chelicerata and Mandibulata, brain regions that reveal profound taxonomic differences can be resolved as homologous by recognizing corresponding ground patterns of axons and dendrites laid down during early development [Strausfeld, 2012]. To take another example: the apparent lack of striosomes in the avian striatum tells us nothing about the evolution of striosomes in other vertebrates, unless they are identified in another chordate subphylum, as has been shown for lamprey [Stephenson-Jones et al., 2013].

The third argument for convergence hinges firstly on a definition for 'brain' and secondly on a resolved root of the phylogenetic tree of Bilateria. First, claiming the implausibility that the protostome-deuterostome ancestor possessed a complex brain raises the obvious question: why should its brain have been 'complex'? Circuits typifying a specific center or a conglomerate of centers are not necessarily complex, and apomorphic elaborations can clearly evolve from ancestral ground patterns [Scholtz, 2004]. Even the smallest hexapods (Collembola), with brains $<100$ micrometers wide, possess a central complex comprising all the components seen in a larger insect but made up of the barest minimum of neurons [Kollmann et al., 2011]. Elementary beginnings are further exemplified by the organization of the central complex in the morphologically simple larvae of holometabolous insects. In the larval beetle Tenebrio molitor, for example, the central complex comprises basic arrangements of decussating pioneer axons intersected by tangential processes, typifying the ground pattern organization of these centers. During larval maturation and metamorphosis to adulthood, the central complex acquires greater intricacy as more types of nerve cells contribute to it [Wegerhoff and Breidbach, 1992]. As does an adult insect, its larva will select actions appropriate to its ecology. If trace fossils identified earlier than the Cambrian indicate the presence of small bilaterians whose trajectories reveal action selection [Chen et al., 2013], then what value are arguments that such an organism could not have accommodated the ground pattern circuitry for action selection?

Homology vs. Convergence in Resolving Correspondences of Brain Organization
The interpretation of homologous ChINs, like those involved in insect and mammalian brain development, relies on resolved cladistics and thus a broad sampling of criteria and species [Hirth and Reichert, 2005]. For example, genes homologous to those defining chordate CNS polarity are expressed along the anteroposterior axis of enteropneusts, a taxon that is considered to reside at the base of the deuterostome lineage and to have a basiepithelial nerve net. However, recent evidence suggests that enteropneusts have dense agglomerations of neurons associated with a neuropil, forming two cords, ventral and dorsal, that resemble a centralized nervous system [Nomaksteinsky et al., 2009]. Moreover, phylogenomic microRNA data refute their basal position in the deuterostome lineage [Peterson et al., 2013], suggesting not only the secondary loss of brain signaling centers during development [Pani et al., 2012], but also of the brain itself in hemichordates [Hirth, 2010].

Thus, both evolutionary gains and losses have to be taken into account. Importantly, secondary reduction or even loss of morphological characters is a far more common adaptation than traditionally appreciated [Jenner, 2004; Hirth, 2010]. Extant brainless deuterostome and ecdysozoan phyla comprise, in the main, sedentary or pelagic species, or motile species, such as nematodes, that occupy uniform and stable ecologies. For example, in the water column, in rivers and even glaciers, all of which offer locally uniform ecologies, evolved loss and drastic reduction of specific brain regions are exemplified by copepods [Andrew et al., 2012], a group providing what is estimated as the largest biomass amongst arthropods [Wiebe et al., 1992]. Similarly, barnacles develop through larval stages possessing a tripartite brain that is secondarily reduced during metamorphosis [Semmler et al., 2008]. In contrast to their sessile adult lifestyle, the larvae are freely moving, with the cyprid larva 'walking' along the seabed to find a suitable site for their final living space. Barnacles thus illustrate the congruence of an animal's ecology with the secondary reduction/loss of a brain.

\section{Deep Homology in Brain Evolution}

A fundamental problem in proposing convergent evolution of bilaterian brains, as advocated by Moroz [2009], Northcutt [2012] and Farries [2013], is the lack of a plausible scenario for underlying mechanisms that explain how convergence could result in the multitude of similarities and minuteness of resemblances, including gene expression, functional attributes and pathologies. An ex- 
emplary case is alcohol addiction mediated by tay-bridge in Drosophila and its AUTS2 gene homolog in mammals, including humans [Schumann et al., 2011], which involves orthologous dopaminergic circuitries modulating, respectively, central complex and basal ganglia activity [for review, see Strausfeld and Hirth, 2013].

Convergent evolution is also challenged by abundant evidence for the stability of ancestral gene regulatory networks (GRNs) [Davidson and Erwin, 2006] and ChINs [Wagner, 2007; Hirth, 2010]. This implies that if GRNs and ChINS in the common ancestor of arthropods and vertebrates specified neuronal ground patterns, those ground patterns are likely to have persisted through geological time. Thus, the multitude of genetic correspondences described by Strausfeld and Hirth [2013] suggests that if those genes were coopted, this would likely have been in the protostome-deuterostome ancestor. Genes that impart unique features of basal ganglia or central complexes in, respectively, vertebrates and arthropods are best explained by their later cooption after the divergence of these two taxa. However, such divergent elaborations manifestly do not obscure the ancestral ground pattern.

Opposed to the principle of parsimony is the idea that convergent evolution provides detailed correspondence of structure and function. This notion would have to postulate the convergent evolution of different but computationally equivalent regulatory interactions provided by genetic networks that determine neural architectures, sensu lato, that function in almost identical ways in vertebrates and arthropods. Yet it is demonstrably homologous genes, such as the Drosophila tay-bridge and murine AUTS2 genes mentioned above, that are expressed and function in a similar manner, such that orthologous action selection circuits in both insects and vertebrates mediate reward behavior and are prone to the same addictive disorders.

Such a minuteness of resemblance is not something that any sensory-motor area of the vertebrate or arthropod brain could perform, as implied by Farries' suggestion that the arthropod central complex as much resembles basal ganglia as it does virtually any other sensorymotor integration region of the vertebrate brain, thereby conveying the impression that all sensory-motor regions in vertebrates look alike [Farries, 2013]. On the contrary, deep homology of brain evolution predicts the retention of a ground pattern for action selection circuitries that can be resolved in extant species.

\section{Conclusion}

A multitude of comparative observations, including those based on recent microRNA and rRNA data [Christodolou et al., 2010; Mallatt et al., 2012], support a common ancestry of arthropods and vertebrates, a conjecture that is further corroborated by recent morphological and molecular evidence suggesting that Cnidaria (Hydrozoa, Anthozoa) represent a true out-group to Bilateria [Steinmetz et al., 2012]. Simpson's signature approach to resolving homology [Simpson, 1961], together with comparative developmental genetics and phylogenomics, provides the strategies and logic used for comparing ground patterns of organization across different taxa. Based on a multitude of similarities, together with the principle of parsimony, these approaches identify homologous ground patterns of the arthropod central complex and vertebrate basal ganglia. They also suggest that 'brainlessness' is an evolved adaptation to an ecology undemanding of an errant life that dictates circuits for contextdependent sensory integration, memories, action selection and directed behavior; in a word, the brain that the protostome-deuterostome ancestor is likely to have possessed.

\section{Acknowledgements}

Supported by grants from the UK Medical Research Council (G070149), Royal Society (Hirth2007/R2), Motor Neurone Disease Association (Hirth/Mar12/6085, Hirth/Oct07/6233), Alzheimer Research UK (Hirth/ARUK/2012), the Fondation Thierry Latran (DrosALS) (to F.H.), the Air Force Research Laboratories (NJS/AFRL FA86511010001) (to N.J.S.) and the Center for Insect Science, University of Arizona, Tucson, Arizona (to N.J.S.).
References
Butler AC, Hodos W (2005): Comparative Vertebrate Neuroanatomy. Evolution and Adaptanicus supports a complex ancestral ground tion, ed 2. Hoboken, John Wiley \& Sons, Inc.
pattern of the tetraconate cerebral nervous Carroll SB (2008): Evo-devo and the expanding systems. J Comp Neurol 520:3446-3470.

Bronner ME, LeDouarin NM (2012): Development and evolution of the neural crest: an overview. Dev Biol 366:2-9. evolutionary synthesis: a genetic theory of morphological evolution. Cell 134:25-36. 
Chen Z, Zhou C, Meyer M, Xiang K, Schiffbauer JD, Yuan X, Xiao S (2013): Trace fossil evidence for Ediacaran bilaterian animals with complex behaviors. Precambrian Res 224: 690- 701 .

-Christodoulou F, Raible F, Tomer R, Simakov O, Trachana K, Klaus S, Snyman H, Hannon GJ, Bork P, Arendt D (2010): Ancient animal microRNAs and the evolution of tissue identity. Nature 463:1084-1088.

Darwin C (1859): On the Origin of Species by Means of Natural Selection, or the Preservation of Favoured Races in the Struggle for Life. London, J Murray.

Davidson EH, Erwin DH (2006): Gene regulatory networks and the evolution of animal body plans. Science 311:796-800.

-Dunn CW, Hejnol A, Matus DQ, Pang K, Browne WE, Smith SA, Seaver E, Rouse GW, Obst M, Edgecombe GD, Sørensen MV, Haddock SH, Schmidt-Rhaesa A, Okusu A, Kristensen RM, Wheeler WC, Martindale MQ, Giribet G (2008): Broad phylogenomic sampling improves resolution of the animal tree of life. Nature 452:745-749.

-Farries MA (2013): How 'basal' are the basal ganglia? Brain Behav Evol 82:211-214.

Geoffroy Saint-Hilaire E (1820): Mémoire sur l'organisation des insectes: troisième mémoire, sur une colonne vertébrale et ses côtes dans les insects apiropodes (lu à l'Académie des Sciences, le 12 février 1820). J Compl Diction Sci Méd 7:271-303.

Ghiselin MT (2005): Homology as a relation of correspondence between parts of individuals. Theory Biosci 124:91-103.

Hirth F (2010): On the origin and evolution of the tripartite brain. Brain Behav Evol 76:3-10.

Hirth F, Reichert H (2005): Basic nervous system types: one or many? in Bullock TH et al (eds): Evolution of Nervous Systems. London, Elsevier, pp 55-72.

-Hirth F, Kammermeier L, Frei E, Walldorf U, Noll M, Reichert H (2003): An urbilaterian origin of the tripartite brain: developmental genetic insights from Drosophila. Development 130: 2365-2375.

-Holland LZ, Carvalho JE, Escriva H, Laudet V, Schubert M, Shimeld SM, Yu J-K (2013): Evolution of bilaterian central nervous systems: a single origin? Evol Dev 4:27.

-Jenner RA (2004): When molecules and morphology clash: reconciling conflicting phylogenies of the Metazoa by considering secondary character loss. Evol Dev 6:372-378.

Kollmann M, Huetteroth W, Schachtner J (2011): Brain organization in Collembola (springtails). Arthropod Struct Dev 40:304-316.

-Ma X, Hou X, Edgecombe GD, Strausfeld NJ (2012): Complex brain and optic lobe in an early Cambrian arthropod. Nature 490:258261.
Mallatt J, Craig CW, Yoder MJ (2012): Nearly complete rRNA genes from 371 Animalia: updated structure-based alignment and detailed phylogenetic analysis. Mol Phylogenet Evol 64:603-617.

Medina L, Reiner A (1995): Neurotransmitter organization and connectivity of the basal ganglia in vertebrates: implications for the evolution of basal ganglia. Brain Behav Evol 46: 235-258.

Mindell DP, Meyer A (2001): Homology evolving. Trends Ecol Evol 16:434-440.

Moroz LL (2009): On the independent origins of complex brains and neurons. Brain Behav Evol 74:177-190.

Morris SC (2003): Life's Solution: Inevitable Humans in a Lonely Universe. Cambridge, Cambridge University Press.

-Nomaksteinsky M, Röttinger E, Dufour HD, Chettouh Z, Lowe CJ, Martindale MQ, Brunet JF (2009): Centralization of the deuterostome nervous system predates chordates. Curr Biol 19:1264-1269.

- Northcutt RG (2012): Evolution of centralized nervous systems: two schools of evolutionary thought. Proc Natl Acad Sci USA 109(suppl 1):10626-10633.

Owen R (1843): Lectures on the Comparative Anatomy and Physiology of the Invertebrate Animals, delivered at the Royal College of Surgeons in 1843. London, Longman, Brown, Green and Longmans.

Owen R (1883): Essays on the Conario-Hypophysial Tract and the Aspects of the Body in Vertebrates and Invertebrates. London, Taylor and Francis.

- Pani AM, Mullarkey EE, Aronowicz J, Assimacopoulos S, Grove EA, Lowe CJ (2012): Ancient deuterostome origins of vertebrate brain signalling centres. Nature 483:289-294.

Patel NH, Ball EE, Goodman CS (1992): Changing role of even-skipped during the evolution of insect pattern formation. Nature 357:339-342.

Peterson KJ, Su YH, Arnone MI, Swalla B, King BL (2013): MicroRNAs support the monophyly of enteropneust hemichordates. J Exp Zool B Mol Dev Evol 320:368-374.

Scholtz G (ed) (2004): Baupläne versus ground patterns, phyla versus monophyla: aspects of patterns and processes in evolutionary developmental biology; in: Evolutionary Developmental Biology of Crustacea. Lisse, Balkema, pp 3-16.

Schumann G, Coin LJ, Lourdusamy A, Charoen P, Berger KH, Stacey D, Desrivieres S, Aliev FA, Khan AA, Amin N, et al (2011): Genomewide association and genetic functional studies identify autism susceptibility candidate 2 gene (AUTS2) in the regulation of alcohol consumption. Proc Natl Acad Sci USA 108: 7119-7124.

-Semmler H, Wanninger A, Høeg JT, Scholtz G (2008): Immunocytochemical studies on the naupliar nervous system of Balanus improvisus (Crustacea, Cirripedia, Thecostraca). Arthropod Struct Dev 37:383-395.
Shubin N, Tabin C, Carroll S (1997): Fossils, genes and the evolution of animal limbs. Nature 388:639-648.

-Shubin N, Tabin C, Carroll S (2009): Deep homology and the origins of evolutionary novelty. Nature 457:818-823.

- Simpson GG (1961): Principles of animal taxonomy. New York, Columbia University Press.

Steinmetz PR, Kraus JE, Larroux C, Hammel JU, Amon-Hassenzahl A, Houliston E, Wörheide G, Nickel M, Degnan BM, Technau U (2012): Independent evolution of striated muscles in cnidarians and bilaterians. Nature 487:231234.

-Stephenson-Jones M, Ericsson J, Robertson B, Grillner S (2012): Evolution of the basal ganglia; dual output pathways conserved throughout vertebrate phylogeny. J Comp Neurol 520:2957-2973.

Stephenson-Jones M, Kardamakis AA, Robertson B, Grillner S (2013): Independent circuits in the basal ganglia for the evaluation and selection of actions. Proc Natl Acad Sci USA 110:E3670-3679.

-Stephenson-Jones M, Samuelsson E, Ericsson J, Robertson B, Grillner S (2011): Evolutionary conservation of the basal ganglia as a common vertebrate mechanism for action selection. Curr Biol 21:1081-1091.

Strausfeld NJ (2011): Some observations on the sensory organization of the Crustaceomorph Waptia fieldensis (Walcott). Palaeo Canadiana 31:157-169.

Strausfeld NJ (2012): Arthropod Brains: Evolution, Functional Elegance, and Historical Significance. Cambridge, Belknap Press of Harvard University Press.

Strausfeld NJ, Hirth F (2013): Deep homology of arthropod central complex and vertebrate basal ganglia. Science 340:157-161.

Striedter GF (2005): Principles of Brain Evolution. Sunderland, Sinauer.

Tanaka G, Hou X, Ma X, Edgecombe GD, Strausfeld NJ (2013): Chelicerate neural ground pattern in a Cambrian 'great appendage' arthropod. Nature 502:364-367.

Telford MJ, Budd GE (2003): The place of phylogeny and cladistics in Evo-Devo research. Int J Dev Biol 47:479-490.

Telford MJ, Copley RR (2011): Improving animal phylogenies with genomic data. Trends Genet 27:186-195.

Wagner GP (2007): The developmental genetics of homology. Nat Rev Genet 8:473-479.

Wegerhoff R, Breidbach O (1992): Structure and development of the larval central complex in a holometabolous insect, the beetle Tenebrio molitor. Cell Tissue Res 268:341-358.

Wiebe PH, Davis CS, Greene CH (1992): Visualizing life in the ocean interior. Oceanus 35 : 100-106.
Homology vs. Convergence in Resolving Correspondences of Brain Organization
Brain Behav Evol 2013;82:215-219 